\title{
Analysis of Comparative English Media Reports that Related to the Aftermath of the Fukushima Daiichi Nuclear Power Plant Disaster
}

\author{
Makoto Sakai \\ Department of Media and Communications, Faculty of Information \& Communications, Bunkyo University, Japan
}

Copyright (C) 2015 by authors, all rights reserved. Authors agree that this article remains permanently open access under the terms of the Creative Commons Attribution License 4.0 International License

\begin{abstract}
I performed a comparative analysis of media reports that related to the aftermath of the Fukushima Daiichi nuclear power plant disaster. I researched advanced countries' media reports on the nuclear power technology field, and especially those from the United States, the United Kingdom, Germany, and France and so on. I focused on researching these countries' news contexts and changes to their nuclear policies, and compared the public opinions on nuclear power policy reflected in each country's media. According to Ulrich Beck, in a society steeped in risks and uncertainty, the existing political system becomes the malfunction, and technology is tinged with political characteristics. Consequently, a new type of democracy that controls risks and uncertainty through academic means becomes needed. I used the framework of sociology and media studies, and my research purpose is to clarify the different contexts for nuclear power policy that Japanese media have not reported well in the above-mentioned countries, and contribute to the enhancement of self-information-governance educational materials about nuclear power technology. Currently, international media companies post news in the newspapers and on their websites in English. They post large amounts of content every day, and update it frequently. For this research, I gathered news texts on the aftermath of the Fukushima Daiichi nuclear power plant disaster from newspapers and websites. For example reports of France and Germany were more realistic among other European countries. It can be said that the response towards nuclear safety of these two governments showed "Contrasted route" to which Japan should refer in the future. Then I categorized them into four groups, to analyze what the media in the above four counties have reported about Fukushima: 'same context' (typical context), 'a different context from other countries' media', 'a changing context from before', and 'proposals for the decommissioning and reconstruction process in Japan'. After all, this nuclear accident in Fukushima is unquestionably "a man-made disaster" occurred by having neglected the improvement of the problem that was bound by the one like
\end{abstract}

"law of the nuclear power village" such as "the nuclear power plant is safe and information disclosure is unnecessary" and pointed out from the outside and the effort of information disclosure. In the near future, what is necessary for Japan is not only the technology around the nuclear reactor but also introduction of "the technology that the civilian observes nuclear power village" composed of the bureaucracy, the academy and the company that have to do with nuclear power generation.

Keywords Media Studies, Sociology, Social Thought, Crisis Management

\section{Introduction}

I performed a comparative analysis of media reports that related to the aftermath of the Fukushima Daiichi nuclear power plant disaster. I researched advanced countries' media reports on the nuclear power technology field, and especially those from the United States, the United Kingdom, Germany, and France and so on. I focused on researching these countries' news contexts and changes to their nuclear policies, and compared the public opinions on nuclear power policy reflected in each country's media.

\section{Research Method and Purpose}

According to Ulrich Beck, in a society steeped in risks and uncertainty, the existing political system becomes the malfunction, and technology is tinged with political characteristics. Consequently, a new type of democracy that controls risks and uncertainty through academic means becomes needed. I used the framework of sociology and media studies, and my research purpose is to clarify the different contexts for nuclear power policy that Japanese media have not reported well in the above-mentioned 
countries, and contribute to the enhancement of self-information-governance educational materials about nuclear power technology.

Currently, international media companies post news in the newspapers and on their websites in English. They post large amounts of content every day, and update it frequently. For this research, I gathered news texts on the aftermath of the Fukushima Daiichi nuclear power plant disaster from newspapers and websites. Then I categorized them into four groups, to analyze what the media in the above four counties have reported about Fukushima: 'same context' (typical context), 'a different context from other countries' media', 'a changing context from before', and 'proposals for the decommissioning and reconstruction process in Japan'.

\section{The US media analysis after the Fukushima Daiichi nuclear power plant disaster}

In general, the US media coverage of the Great East Japan Earthquake and the Fukushima Daiichi nuclear accident can be said to have been better than that of other countries' media immediately after the earthquake, a year after the earthquake, and even two years after. The US media sent a larger number of reporters and journalists to Japan than other countries did, and played an important role in the Japanese media industry by launching websites written in Japanese. For example, immediately after the earthquake, on 25 March 2011, The Wall Street Journal (WSJ) reported on labour issues at the nuclear accident site. The article was worthy of representing the world as an economy report. According to that article, we should not pay attention to the workers who received good treatment, who were referred to as the 'Fukushima 50'. We should pay attention to the several hundred people who worked without regard to risk for a monthly salary of $\$ 2,470$, such as the Tokai painting employees who were engaged in dismantling the rubble and transporting pipes in high-radiation areas. The remuneration of the workers involved in the decommissioning works is quite low even now, and there is a large gap in remuneration between corporate contractors/subcontractors and lower-tier subcontractors, which is now a major factor in increasing the separation among workers. This is why the immediate WSJ report after the nuclear accident can be said to have proactively captured the problems that are occurring even today. WSJ has launched not only a Japanese version of its news site, but also a site called Fukushima Watch that provides accurate news from Japan written in English. This site has continued to deliver news about the ongoing decommissioning works at the Fukushima nuclear power plant to the world.

One year after the earthquake, on 12 March 2012, the New York Times (NYT) published an article entitled 'An Anniversary of "Heartbreaking Grief" in Japan' at the top of its international page.[1] In this article, NYT included a map centred on Fukushima Prefecture and summarized the short history of the nuclear accident after the Great East Japan Earthquake. It also reported on the municipalities around the nuclear power plants, such as Okuma, Namie, and
Minamisoma, that suffered secondary damage. For example, the article pointed out that there were some misjudgements and poor instructions regarding the prevention of radiation damage and the evacuation of refugees because the System for the Prediction of Environmental Emergency Dose Information (SPEEDI) data was not opened right after the nuclear accident. There were also disparities related to the compensation and reconstruction of the disaster area. Other problems were caused by the site's bad reputation: right after the disaster, some private bus companies refused to send buses to the site because they were afraid of rumours, so Namie residents were delayed in their flight from the radiation. In Minamisoma, it became clear after the analysis of the dead bodies that five refugees died not from the earthquake and tsunami, but from starvation due to how little food and water was available right after the nuclear accident. Generally speaking, in Japan, there were few detailed reports of secondary disasters because everybody wanted to forget about the problem and refused to take responsibility. The NYT reports above reveal such blind spots.

In contrast, an NYT article from 12 March 2014 mentioned Japan's recovery from the earthquake and nuclear accident from the perspective of consumers, rather than from an administrative point of view. That day's top article and the page B2 article contained interviews with women who are living in Kobe and accumulating 500-yen coin savings.[2] Internationally, commodity prices have been rising and monetary value has been falling. However, in Japan, most people have grown accustomed to deflation, so 'drawer savings' and '500-yen coin savings' are very popular. I believe this is why NYT was interested in the money-saving habits of Japanese women. NYT also reported on familiar examples for consumers, such as the price increases at discount ramen shops in Tokyo, the weaker yen, and the higher price advances in Japan. Building material costs and labour costs are higher than before, so the restoration of the disaster area is not going well. According to the editorial page on that day, 1,607 people in Fukushima died in the earthquake, while more than 3,000 people died of suicide or health problems after the earthquake; thus, the reconstruction of life in Fukushima has been delayed.

Michael Sandel, who is known as the professor of "Justice," a law course offered by Harvard University and viewable online, began one lesson with the question of what "justice" meant in the hurricane-stricken area when the security situation deteriorated. Sandel asked his class whether they agreed that price hikes in the stricken area were opportunistic. As he explained, "in this case, there were two different type of justice functioning.

Justice, type one: An opportunistic price hike at the time of a disaster was an act in accordance with market mechanisms; through it, suppliers would have been able to spread goods and services quickly, so looking at things in the long term, people had a reason to accept price hikes in goods and services in the name of economic freedom.

Justice, type two: When everyone is in trouble, like in a disaster, opportunistic price hikes are a vice, under an idea of 
"cherishing the mutual help which does not need money, so people could accept the happiness based on priceless communalism."

I think type-one justice is the type, which existed in New Orleans just after the hurricane, and type two is the "collective unconscious" which existed in Japan immediately after the earthquake and tsunami. In other words, in the US, although there was individual freedom in the hurricane-stricken area, a communal morality did not function. On the other hand, in Japan, although there was a lack of individual freedom in the stricken area, there was certainly friendship and communalism.

The reason US media reported the behavior of disaster victims in Japan as remarkable is that these people understood the values of type-two justice and communal morality. So US media were, for instance, in love with quoting the fact that the Japanese mafia (the yakuza) had not stolen anything during the disaster, but instead supported disaster victims" after both the Great Hanshin Earthquake in 1995 and the Tohoku earthquake and tsunami. Probably, these reports included surprise that "the morality of communalism pervade even to Yakuza."

Of course, another factor is that the United States is a multiethnic nation, so it is more difficult for the residents of a stricken area to get together as one community and maintain order.

Generally speaking, even after the Great East Japan Earthquake, US media sources such as WSJ and NYT reported on details about Japan's reconstruction and nuclear accident aftermath based on local research and daily life coverage. Japan and the US shared a lot of information and human relationships after WW2, and the two countries have a long history of knowing each other well. I think the reason why the US media coverage was so good is also because the US has over 100 nuclear power plants, so US citizens have been strongly interested in the fact that Japan has faced danger since the earthquake and nuclear accident.

\section{The UK media analysis after the Fukushima Daiichi nuclear power plant disaster}

In contrast to the US media and its influence, UK media reports on the earthquake and nuclear disaster were few and brief. Immediately after the earthquake, because of how few resident reporters they had in Japan, the UK media published many incorrect reports in their newspapers and websites. This played an important role in expanding the reputational damage to Japan. For example, the BBC reported on 11 March 2011-with an accompanying photograph-that 'almost all of Sendai city area, in which about 1 million people live, has sunk, and only a few buildings remain'.[3] In fact, only Wakabayashi-ku and Miyagino-ku, near the seaside, had sunk, while almost all of the Sendai area escaped with little damage. Similarly, an article in the Guardian on 29 March reported: "Fukushima meltdown fears rise after radioactive core melts through vessel".[4] Although the melting of fuel pellets and leaking of cooling water had already taken place, at that time it was not clear that 'the reactor core which melted pierced through the container'.

Of course, such misinformation appeared not only in the UK media but also in other countries' media, including the US, France, and China. Though the international influence of the UK media is very strong, international UK media such as the BBC and the Guardian spread misinformed reports. I think the UK media has a responsibility to counter this exaggerated image of Japan as a disaster area.

Yet, as time has passed since the earthquake and nuclear disaster, the UK media have not only reported news that inflamed the crisis, but also shared their own problems, as the UK also has many nuclear power plants in its domain. For example, in an article from 12 March 2012, the Times stated that the Emperor attended the Great East Japan Earthquake memorial ceremony, and reported that it was not only a memorial for the victims, but also a memorial for the end of many towns and communities.[5] Certainly, the earthquake and the nuclear accident involved not only the tsunami and nuclear radiation, but also life-threatening human damage related to the social system that maintains the community. In the three years since the earthquake, projects such as the reconstruction of compact cities, which gather dispersing residents in disaster areas, have been realized, but this is not enough to rebuild these communities. It is interesting that the Times focused on the community damage one year after the earthquake. This is characteristic of the UK media, which is based on parish (municipality) foundations and a high consciousness of autonomy related to the origins of parliamentary democracy.

However, probably because the UK media have been faced with harsh circulation competition, they publish extreme opinions in order to stand out in the public eye. A Times article from 11 March 2014 is a symbol of such severe media competition in UK. Provocative headlines such as 'Dump Fukushima waste into the sea' demonstrate extreme article content not seen in the quality newspapers of other countries.[6] This article was based on an interview with Dale Clain, the chief regulatory officer of the US nuclear industry, who proposed that "Because tritium is not an isotope that builds up in the body. There are world standards for tritium release". It seems a controversial opinion, but in the UK there was an incident discovered in 2013 in which tritium had been spilled in the basement of the Dungeness nuclear power station, which ceased operations in December 2006. I think the Times' Fukushima report was so controversial because they had experienced a tritium crisis in the past. Certainly, the Times' proposal is reasonable: in Fukushima, although the multi-species removal device ALPS has already removed 62 types of radioactive material, it cannot remove tritium, so it has not been releasing contaminated water into the sea. Considering international standards, it is a major problem that TEPCO has continued to accumulate contaminated water in many tanks, because the tritium cannot be removed. On the other hand, some scholars have pointed out that ALPS was unable to adequately remove not only tritium, but also strontium. Meanwhile, 
TEPCO has not been able to control the contaminated water at the Fukushima Daiichi nuclear power plant, even when the removal of radioactive material using ALPS was successful except for tritium and strontium.

For example, at first TEPCO had not identified the reactor vessel sites of leaking containment water at Fukushima, so they could not undertake the repair of the storage container. Therefore, TEPCO could not efficiently flood the containment vessel of cold nuclear fuel debris. Second, TEPCO could not have prevented this debris from flowing into the primary groundwater site, as there was no way to make an impervious wall of frozen soil around the reactor buildings. For this reason, even now, nearly half of the workers in the field are engaged in work to prevent contaminated water rather than decommission nuclear power plants. In other words, the recovery process of the Fukushima Daiichi nuclear power plant accident had already been stalled due to previous problems, before the release of tritium.

The Times article from 12 March 2014 is also controversial. It reported, below the heading 'Nuclear Reaction': 'Shinzo Abe is right. It is time for Japan to return to nuclear power'.[7] Yet, this opinion was excessively optimistic. In contrast, there were few Japanese media reports that agreed with the re-opening of nuclear power plants. Even if TEPCO and the Japanese government do not need to adopt the extreme opinion of the Times, I believe they should consider a compromise plan that re-opens nuclear power plants that have passed stress tests and meet the new safety standards. They should then aim to decommission older nuclear power plants that have been in operation for over 30 years and have completed depreciation.

3 The France media analysis after the Fukushima Daiichi nuclear power plant disaster.

Reports in France and Germany were more realistic than those in other European countries. It can be said that the response to nuclear safety of these two governments took a contrasting route to the one taken by Japan, and one to which Japan should refer in the future. For example, the French international media source France 24 reported right after the Fukushima nuclear accident, 'They want the ageing reactor shut down immediately, but most French people see no urgent need to close it down'.[8]

France operates 59 nuclear power plants and supplies about $77 \%$ of its electric power through nuclear power generation, in part as a result of its loss of the colony of Algeria, which had large natural gas and oil resources, in 1962.[9] Moreover, the world's largest nuclear power conglomerate, AREVA, is French. Government-affiliated organizations own about $90 \%$ of AREVA stock and are involved in the handling of nuclear fuel and the manufacturing of nuclear reactors. AREVA's involvement with the nuclear accident at Three Mile Island in 1979 and decommissioning work, requiring advanced techniques, after the Chernobyl nuclear accident in 1986 have made AREVA into a walking dictionary of the world's nuclear accidents.
At the end of March 2011, not only the CEO of AREVA but also French President Nicolas Sarkozy came to Japan to discuss a scheme for AREVA to take the place of the American company General Electric, whose techniques and equipment had been used at the Fukushima Daiichi plant. In fact, AREVA contracted with TEPCO at the beginning of April 2011 to work on the processing of heavily radioactive water at Fukushima. AREVA's technology has already been used at Rokkasho village in Aomori in north part of Japan for processing heavily polluted water, but it is difficult to say whether this process obtained adequate results. The reprocessing plant at Rokkasho has not yet been completed, although it was approved in 1989 with a budget of $¥ 760$ billion and was intended to be completed by 1997 . According to a report in February 2011, the cost of construction has more than tripled to $¥ 2,193,000,000,000$. In light of this case, Japan should be careful about introducing AREVA technology to Japanese nuclear plants on a large-scale, beyond simple decommissioning. I wonder if the French government and France 24 have a close relationship with the nuclear industry as a national policy, since their criticisms of the Japanese government are harsh, but not as much as those of the French government and nuclear industry.

The nuclear accident in Fukushima was unquestionably a manmade disaster occasioned by the neglect of a problem, as well as laws such as the so-called 'law of the nuclear power village', which stated that 'the nuclear power plants are safe and information disclosure is unnecessary'. In the near future, it will be necessary for Japan not only to improve reactor technology but also to introduce strong civilian oversight of the 'nuclear power village' with the participation of the bureaucracy, the academy, and the companies involved in nuclear power generation.

4. The Germany media analysis after the Fukushima Daiichi nuclear power plant disaster.

Almost simultaneously with the nuclear accident in Fukushima, anti-nuclear power demonstrations were held in many cities in Germany. The German Green Party has a growing approval rating now equal to that of the governing Christian Democrats. Therefore, Federal Chancellor Angela Merkel has declared a 180-degree turnaround in nuclear policy for the "future abolition of the nuclear power plant and shift to renewable energy'. [10] Can Japan realistically follow this movement away from nuclear power?

The largest proportion of power generated in Germany is thermal power from coal, accounting for $44.78 \%$ of the total.[11] Coal is productive in terms of power, and Germany produces the most brown coal (coal with a lot of impurities) in the world, too. In other words, Germany covers its power needs mostly with abundant domestic coal and brown coal. However, coal power has a negative environmental impact. In particular, brown coal is energy-inefficient and is collected by open-pit mining that destroys the natural environment. Because of its post-nuclear policy, promotion of renewable energy, and expanding Green party, Germany 
might be seen as environment-friendly country at first glance. In fact, Germany is a country that mines a large amount of coal and brown coal and has a high environmental impact.

Nuclear power accounts for $22.84 \%$ of German power generation, natural gas $13.03 \%$, and oil only $2.12 \%$. In Japan, nuclear power is almost the same amount $26.91 \%$, natural gas $26.33 \%$, and oil $8.68 \%$. Germany has a $32 \%$ self-sufficiency ratio in energy, but in Japan, this figure is only 5\% (2009). Some self-sufficiency in Germany is relatively assured, because there is abundant coal and brown coal even if nuclear power generation stops. However, in Japan it is difficult to stop nuclear power generation because of the lack of alternatives. Moreover, Japan can neither import electric power from France in case of emergency like Germany can nor import natural gas by pipeline from Russia.

In this situation, it can be said that large-scale installation of thermal power plants and import of raw materials are necessary for Japan to aim to break with nuclear power. Japan is already the most dependent country in the world on crude oil imports from the Middle East, but must this situation continue? Or, can a pipeline from Russia deliver a high volume of natural gas and oil? Or, can a resource like methane hydrate, of which major reserves exist in the Sea of Japan, be gathered by new technology? In any case, the type and source of fuel is crucial if Japan is to cover a possible electricity shortage. The decision is likely to become important to Japanese diplomacy in the future.

As a premise, electricity prices are an important factor that affects the export competitiveness of a given country. According to data from the Central Research Institute of the Electric Power Industry, Japan has seen rising electricity prices for both homes and industries, and industry prices are especially high compared to those of other developed countries-about three times that of the US and 1.5 times that of France.[12] When one critically analyses the media coverage of Germany, one sees that if the weaker yen advances and the price of natural gas and oil soar in the future, there will be economic incentives for Japan to use nuclear power plants rather than renewable energy, as most of Japan's nuclear power plants experienced no damage in the Great East Japan Earthquake of 2011.

\section{Conclusions}

When TEPCO made the Fukushima Daiichi nuclear power plant import GE technology from the US, they relied on the 'safety myth'. For example, they shaved the ground by 20 metres where it was originally about 30 metres above sea level in order to reduce the cost of pumping cooling water into the nuclear power plant. TEPCO also set two emergency power supplies side by side on the sea side of the underground level, whereas they should have set that equipment in different places on the ground level. It is obvious that such basic construction mistakes caused the nuclear power plant disaster in 2011. In addition, even after the tsunami hit the nuclear power plants, there were human errors - such as misunderstandings about the state of nuclear fuel cooling and miscalculations of water pressure in the power plant pipes - caused by a lack of staff training. Not only TEPCO but also the Japanese government and media have failed to report the details of these human errors to the public because they do not want to divide the country, so they have shifted the responsibility for the crisis onto the natural disasters. Many people have not examined or pointed out these human errors; they have simply expressed a vague anxiety about the re-opening of the nuclear power plant and enhanced the awareness of the anti-nuclear power movement in Japan.

The role of the media and journalism is primarily to present different points of view (other opinions) and to make this vague anxiety public. The media of the US, UK, France, and Germany, while also embodying interests related to their own countries' nuclear power policies, have proposed controversial alternative perspectives. I think these proposals are useful for decommissioning nuclear power plants and reconstructing communities and infrastructure after the Japanese earthquake and nuclear disaster. I believe that without the future contributions of Japanese media and scholars to the autonomy of information about nuclear policy, it will be impossible to realize either denuclearisation or the effective use of nuclear power.

\section{REFERENCES}

[1] An Anniversary of 'Heartbreaking Grief' in Japan, New York Times March 12, 2012

[2] Yen-Pinching Undercuts Japan's Push Against Its Years of Deflation, New York Times March 11, 2014

[3] Japan earthquake: A week in pictures, BBC March 11, 2011

[4] Japan radiation leaks feared as nuclear experts point to possible cover-up, guardian March 29

[5] Sobs break the silence one year on from tsunami, The Times March 12, 2012

[6] Dump Fukushima waste into the sea, Japan urged, The Times March11, 2014

[7] Nuclear Reaction Shinzo Abe is right. It is time for Japan to return to nuclear power, The Times March11, 2014

[8] The nuclear plant that Germans want shut down- in France, France 24 April 18, 2011

[9] International Energy Agency ENERGY BALANCES OF OECD COUNTRIES (2010 Edition)

[10] German government plans total nuclear shutdown by 2022 , Deutsche Welle May 30, 2011

[11] International Energy Agency ENERGY BALANCES OF OECD COUNTRIES (2010 Edition)

[12] Central Research Institute of Electric Power Industry report April 30, 2011 
[13] Ulrich Beck. World at Risk. Polity. 2008. 240p

[14] Michael J. Sandel. Justice: What's the Right Thing to Do? Farrar Straus \& Giroux. 2010.308p

[15] Sakai, Makoto. Fukushima which the world witnessed. Shincho45. 30(6). 2011. 115-121.

[16] Sakai, Makoto. Fukui, Hiromichi. Ontology Study for Analysis and Anatomy of English-language News Relating to
Human Security. Interdisciplinary Ontology. Vol.3. 2010. 145-154.

[17] Kume, Ikuo. Kojyo, Keiko. Mabuchi, Masaru. Kawade, Yoshie. Polotical Science: Scope and Theory. Tokyo. Yuhikaku. 2003. 534p. New Liberal Arts Selection.

[18] Ninomiya Shoten editors. Data book of the world. Tokyo. Ninomiya Shoten. 2011. 496p. 